\title{
0 powiatach i folwarkach. Kulturowe i lingwistyczne uwarunkowania przekładu wybranych terminów historycznych na język angielski
}

\author{
Paulina Wactawik \\ https://orcid.org/0000-0002-2321-7179 \\ Uniwersytet Warszawski
}

Zarys treści: Celem artykułu jest prezentacja i analiza licznych problemów, jakie pociąga za sobą przekład tekstów dotyczących historii i geografii danego regionu. Tekst zilustrowany jest przykładami powiązanymi z podziałami struktury administracyjnej i społecznej w Polsce, do których należą: województwo, powiat, wójt, miasto, folwark, zagrodnik i komornik. Analiza ma charakter dwutorowy i obejmuje metodologiczne aspekty procesu tłumaczenia oraz status ontologiczny słów i przedmiotów, do których słowa te się odnoszą. Analizowane są trzy główne zagadnienia: 1) rozbieżność i nakładanie się kategorii związanych z lokalnymi systemami administracyjnymi, 2) zróżnicowanie słów w zależności od lokalizacji oraz 3) ich ewolucja w czasie. Na koniec zaproponowano i omówiono jednolity sposób prezentacji wszystkich cech i zastrzeżeń, jakie należałoby uwzględnić przy wyborze najwłaściwszego odpowiednika. Przedstawiono to $\mathrm{w}$ formie tabeli, która uwzględnia wszystkie argumenty wymienione w tekście.

Słowa kluczowe: tłumaczenia kulturowe, jednostki administracyjne, ekwiwalencja, geohistoria

Czy król w XVI w., podróżując po Rzeczypospolitej, jeździł po angielskim voivodship czy palatinate? Czy jeśli opowiadamy czytelnikowi z Włoch albo Chin o powiatach w Prusach Książecych, to czy mówimy o districts czy counties? Czy szlachta polska, spotykając się w folwarku, odwiedzała manor house czy manor demesne? A przede wszystkim: jak nie stracić wszystkich informacji i kontekstów jakże ważnych dla przekazania i zrozumienia narracji historycznej?

W swojej codziennej pracy tłumacz wielokrotnie staje przed dylematem
Abstract: The article aims to present and analyse a range of problems that arise in translating texts on the history and geography of a particular region. It is illustrated with an array of examples connected to the administrative and social structure divisions in Poland, which are as follows: województwo, powiat, wójt, miasto, folwark, zagrodnik, and komornik. The analysis is twofold and includes the methodological aspects of the translation process and the ontological status of the words and objects they relate to. Three major issues are scrutinised: 1) the divergence and overlap of the categories relating to the local administrative systems, 2) the diversity of the words depending on the location, and 3) their evolution in time. Finally, a uniform way to present all features and reservations necessary to be included in choosing the most appropriate equivalent is proposed and discussed. It is operationalised in the form of a table to account for all the arguments mentioned in the text.

Keywords: cultural translations, administrative units, equivalence, geohistory

nieprzekładalności kulturowej, czyli niemożności przekazania treści tekstu oryginału ze względu na uwarunkowania historyczne, systemowe czy nawet światopoglądowe, który to mit nieprzekładalności obala Krzysztof Hejwowski ${ }^{1}$. Mimo istnienia wspólnoty doświadczeń i kultur, do których tłumacz stara się odwołać ${ }^{2}$, wyzwania, jakie stawia tłumaczenie, moga wynikać z globalizacji, która - pozornie

\footnotetext{
${ }^{1}$ K. Hejwowski, Kognitywno-komunikacyjna teoria przekładu, Warszawa 2006. ${ }^{2}$ Tamże.
} 
odchodząc od znaczenia przestrzeni geograficznej - zaniedbuje jednocześnie istotę kulturowych uwarunkowań z niej wynikających $^{3}$. Już na poziomie globalnej polityki możemy przytoczyć przykład tłumaczenia świadectw uchodźców, które są źle interpretowane i świadomie bądź nie „poprawiane", aby lepiej wpasować się w sposoby myślenia grupy, do której są kierowane $e^{4}$. Czasem nawet instytucje mające na celu zacierać granice i podziały między nacjami, jak UNESCO, utwierdzają i pogłębiają te różnice przez tłumaczenia utwierdzające stereotypy, np. przekładając hiszpańskie angiguos mexicanos jako Indians, a sabios, które oznacza mędrców, jako diviners, oraz testimonias jako written records, wypaczając przekaz całego tekstu ${ }^{5}$.

Tłumaczenia tekstów naukowych dotyczących historii wydają się być przykładem szczególnym, ponieważ łączą dwie kategorie wspomniane przez Hansa Vermeera: tłumaczenia „pierwotne” (ang. primary), gdzie kluczowe jest nawiązanie komunikacji pomiędzy nadawcą a odbiorcą tłumaczenia, oraz „wtórne” (ang. secondary), w których istotniejsze jest przekazanie informacji tak, jak to odbiera czytelnik treści w języku oryginału ${ }^{6}$. Rodzi to wiele wyzwań, które zostaną omówione na przykładzie systemów jednostek osadniczych i struktur społecznych. Problemy te można sprowadzić do trzech kwestii:

I. Czy nazwy systemów kategorii, nie tylko osadniczych, w języku oryginału, w naszym przypadku - polskim i w języku docelowym (angielskim), odpowiadają sobie i jak będzie je rozumieć obrana grupa odbiorców tłumaczenia?

\footnotetext{
${ }^{3}$ Zob. M. Baker, Translation and Conflict. A Narrative Account, London 2006; L. Venuti, The Scandals of Translation. Towards an Ethics of Difference, London-New York 1998.

${ }^{4}$ M. Baker, Translation and Conflict.

${ }^{5}$ L. Venuti, The Scandals of Translation.

${ }^{6}$,»Primary « translations are intended to »establish communication between a source-language sender and a target-language recipient«, whereas "secondary « translations are intended to inform a starget-language recipient about a communication between a source-language sender and a source language recipient"", K. Reiss, H.J. Vermeer, Towards a General Theory of Translational Action. Skopos Theory Explained, Hoboken 2014, s. 48.
}

II. Czy i w jaki stopniu znaczenie thumaczonego pojęcia zmieniało się w zależności od lokalizacji?

III. Czy i w jakim stopniu znaczenie tłumaczonego terminu zmieniało się w czasie?

W odpowiedzi na powyższe pytania rozważymy różne pojęcia i terminy, ich funkcjonowanie, znaczenia i ewolucję w obu językach, aby na końcu zaproponować spójny sposób oceny i wyboru najlepszego odpowiednika w zależności od obranych kryteriów. Zaproponowana metoda ma być narzędziem wspierającym autora i tłumacza w wyborze najodpowiedniejszych dla nich strategii. Ponieważ przykłady, którymi ilustrowany jest wywód, są zmienne w czasie i przestrzeni, aby ujednolicić, domyślnie podawane są pojęcia staropolskie.

\section{Teorie w repertuarze ttumacza tekstów z dziedziny geografii i historii}

$\mathrm{Na}$ początek, warto przyjrzeć się klasycznemu rozróżnieniu Romana Jakobsona, który wymienia trzy typy tłumaczenia: wewnątrzjęzykowe (czyli w ramach jednego języka), międzyjęzykowe (z języka oryginału na język docelowy) i międzysemiotyczne (z jednego zestawu znaków na inny, np. na system znaków drogowych ${ }^{7}$, i uzupełnić je o zastrzeżenie, że kategoria międzyjęzykowa jest za wąska i właściwie powinna być zastąpiona przez międzykulturową (ang. intercultural). Prowadzi nas to do głębszych rozważań na temat roli kultury w tłumaczeniu. Zajmuje się tym teoria skoposu, która zakłada, że tłumaczenie jest funkcją celu (gr. skopos), jaki mu przyświeca, a cel z kolei wynika bezpośrednio z docelowej grupy odbiorców treści. Zatem to, jaką przyjmiemy metodę (tłumaczenie ,słowo w słowo, dosłowne, wierne, semantyczne, wolne, komunikacyjne czy adaptacja) ${ }^{8}$ czy też strategię (przeniesienie, wymiana, tłumaczenie, modyfikacja, transkrypcja/transliteracja, dodanie,

\footnotetext{
R. Jakobson, On Linguistic Aspects of Translation, w: On Translation, ed. R.A. Brower, New York 1966

${ }^{8}$ P. Newmark, Textbook of Translation, Herforshire 1998
} 
objaśnienie) ${ }^{9}$, wynika z tego, do jakiej grupy kierujemy nasz przekaz. Na potrzeby naszych rozważań posłużymy się wykorzystywanym przez Piotra Kwiecińskiego rozróżnieniem na strategię domestykacji i egzotyzacji (ang. domestication/foreignisation ${ }^{10}$. Gdy szukając najodpowiedniejszego ekwiwalentu, będziemy odnosić się do systemu oryginału (np. wartości, kategorii, administracyjnego), będziemy mówić o egzotyzacji, a gdy do systemu grupy docelowej - o domestykacji.

Drugim tematem niezbędnym w dyskusji o przekładzie terminologii jest ekwiwalencja, rozumiana przez Wernera Kollera jako koncept determinowany przez uwarunkowania historyczno-kulturowe, wpływające zarówno na tekst oryginału, jak i tekst docelowy, które manifestują się pod postacią często sprzecznych i trudnych do pogodzenia cech językowych, tekstowych i pozajęzykowych ${ }^{11}$. Koncepcja ekwiwalencji wywodzi się od Eugene'a Nidy, który w kontekście całego tłumaczenia rozróżniał ekwiwalencję formalną i dynamiczną. Pierwsza odpowiadała tłumaczeniu nakierowanemu na dosłowne przełożenie treści oryginału, a druga skupiała się na znaczeniu tekstu ${ }^{15}$. Na potrzeby naszych rozważań, przytoczymy trzy rozróżnienia:

Odnosząc się do trzech powyższych taksonomii w kontekście tłumaczenia nazw jednostek osadniczych w różnych momentach w czasie (ang. time snapshots), interesuje nas, w jaki sposób terminy, którymi się posługujemy, odpowiadają terminom występującym w oryginale, czyli ekwiwalencja denotacyjna i konotacyjna, oraz jak kształtuje się całość terminologii zawartej w tekście.

Pojęcia, którymi operowano w przeszłości, są ściśle związane z kulturą i społecznością, której dotyczą, a więc drugim aspektem teoretycznym, warunkującym tłumaczenie terminów i pojęć historycznych jest to, w jaki sposób je kategoryzujemy i wiążemy z kulturą, w której funkcjonują: autor, tłumacz oraz odbiorca tekstów. Fakt istnienia związku pomiędzy postrzeganiem świata a językiem znany jest w językoznawstwie jako hipoteza Sapira-Whorfa ${ }^{16}$. Razem z teoria prototypu ${ }^{17}$, zakładająca, że nasze doświadczenia przypisujemy do pewnych kategorii właściwych

\begin{tabular}{|c|c|c|}
\hline $\begin{array}{l}Z \text { punktu widzenia tekstu i języka } \\
\text { Koller wymienia następujące ramy } \\
\text { warunkujące ekwiwalencję }^{12} \text { : }\end{array}$ & $\begin{array}{l}\text { Reiss i Vermeer natomiast przytaczają } \\
\text { ekwiwalencję }^{13} \text { : }\end{array}$ & $\begin{array}{l}\text { Mona Baker rozróżnia ekwiwalencję na } \\
\text { poziomie }^{14} \text { : }\end{array}$ \\
\hline pozajęzykowe okoliczności, & denotacyjną (denotative Äquivalenz), & słów, \\
\hline konotacje, & $\begin{array}{l}\text { konotacyjną (konnotative } \\
\text { Äquivalenz), }\end{array}$ & fraz, \\
\hline normy językowe, & gatunkową (textnormative Äquivalenz), & struktur gramatycznych, \\
\hline $\begin{array}{l}\text { sposób uwzględnienia odbiorcy } \\
\text { (Empfangerbezug), }\end{array}$ & $\begin{array}{l}\text { pragmatyczną (pragmatische } \\
\text { Äquivalenz), }\end{array}$ & całego tekstu (struktura informacji), \\
\hline $\begin{array}{l}\text { estetyczne aspekty i właściwości } \\
\text { tekstu. }\end{array}$ & formalną (formale Äquivalenz). & całego tekstu (spójność). \\
\hline
\end{tabular}

${ }_{9}^{9}$ B. Poluszyński, Strategie ttumaczeniowe stosowane podczas przekładu nazw własnych na przykładzie wybranych polsko-angielskich artykutów z Wikipedii - analiza jakościowa i ilościowa, , „ęzyki Obce w Szkole”, 4, 2012.

${ }^{10}$ P. Kwieciński, Disturbing Strangeness. Foreignisation and Domestication in Translation Procedures in the Context of Cultural Asymmetry, Torun 2001

${ }^{11}$ W. Koller, The Concept of Equivalence and the Object of Translation Studies 1, „Target. International Journal of Translation Studies”, 7 (2), 1995.

${ }^{12}$ W. Koller, The Concept of Equivalence, s. 197.

${ }^{13}$ K. Reiss, H.J. Vermeer, Towards a General Theory.

${ }^{14}$ M. Baker, In Other Words. A Coursebook on Translation, Abingdon Oxon 2006
${ }^{15}$ E. Nida, C. Taber, The Theory and Practice of Translation. With Special Reference to Bible Translating, Leiden 1982.

${ }^{16}$ B.L. Whorf, Language, Thought, and Reality, ed. J. Carroll, Cambridge, Massachusetts 1957.

${ }_{17}$ G. Lakoff, M. Johnson, Metaphors we live by, Chicago 2003; R.W. Langacker, Investigations in Cognitive Grammar, Berlin-New York 2009 (Cognitive Linguistics Research, 42); E. Rosch, Cognitive Representations of Sematnic Categories, „Journal of Experimental Psychology”, 104 (3), 1975. 
dla danej kultury i że są przykłady bardziej i mniej „centralne” dla danej kategorii, były przyczynkiem do późniejszych badań nad transferem językowym. Badania takie zakładają, że posługując się więcej niż jednym językiem, musimy operować na wielu zestawach kategorii, które na siebie nawzajem oddziałują ${ }^{18}$. Jedną z ciekawych obserwacji jest wpływanie nowo nabytych sposobów rozróżniania na utrudnione kategoryzowanie tych obiektów w języku ojczystym. Przykładem może być nauczenie grupy osób mówiących po angielsku nowego sposobu kategoryzowania szklanek i kubków (ang. cup, mug, glass; ros. чашка, рюмка, кружка, стакан, фужер), który następnie wpłynął na rozróżnienie tych kategorii w języku ojczystym ${ }^{19}$. Teza o znaczącym wpływie sposobów kategoryzowania, wynikającego przede wszystkim z języka i kultury, jest też potwierdzona w badaniach $\mathrm{z}$ dziedziny neurobiologii nad interoceptywną siecią w mózgu ${ }^{20}$. Wszystko to rzuca nowe światło na pracę tłumacza występującego w roli mediatora między dwoma systemami językowymi i kulturami, a co za tym idzie sposobami postrzegania świata ${ }^{21}$. Teorie prototypu w ostatniej części naszych rozważań pozwolą zaproponować sposób na wybór pomiędzy różnymi ekwiwalentami pojęć i terminów. Dzięki zrozumieniu, że mają one charakter rozmyty, a nie binarny (0-1) możemy w zależności od ważnych dla nas cech wybrać taki odpowiednik, który najlepiej będzie funkcjonował w całym tekście (ekwiwalencja na poziomie całego tekstu według Mony Baker).

\footnotetext{
${ }^{18}$ B.C. Malti in., What Constrains Simultaneous Mastery of First and Second Language Word Use?, ,International Journal of Bilingualism”, 20 (6), 2016; A. Pavlenko, S. Jarvis, Bidirectional Transfer, „Applied Linguistics”, 23 (2), 2002; A. Pavlenko, B.C. Malt, Kitchen Russian. Cross-Linguistic Differences and First-Language Object Naming by Russian-English Bilinguals, „Bilingualism. Language and Cognition”, 14 (1), 2011.

${ }^{19}$ A. Pavlenko, B.C. Malt, Kitchen Russian.

${ }^{20}$ L. Feldman Barett, How Emotions Are Made. The Secret Life of the Brain, New York 2017; Handbook of Emotions, eds. L. Feldman Barett, M. Lewis, J. Haviland-Jones, New York 2016.

${ }^{21}$ K. Reiss, H.J. Vermeer, Towards a General Theory, s. 25.
}

Trzecim aspektem teoretycznym, niezbędnym dla naszych dalszych rozważań, jest podejście do jednostek osadniczych i ich zmian ontologicznych w czasie i przestrzeni. Już dla samych historyków kwestia trwałości jednostek osadniczych jest sporna $^{22}$, reprezentacja zaś takich jednostek w bazach danych wydaje się być jeszcze bardziej złożonym problemem ${ }^{23}$. Na potrzeby tłumaczenia nazw typów jednostek osadniczych przyjrzyjmy się rozważaniom Pawła Garbacza i Agnieszki Ławrynowicz dotyczącym trzech kluczowych aspektów dla tożsamości jednostki osadniczej: 1) Czy miejscowość $A B C$ istniała w roku YYYY?, 2) czy miejscowość ABC kiedykolwiek zmieniła lokalizację i 3) kiedy przestała istnieć? ${ }^{24} \mathrm{~W}$ odpowiedzi na te pytania wymieniają oni szereg transformacji, którym poddana może być miejscowość, tj. zmiana nazwy, translokacja czy połączenie $^{25}$.

\section{Ekwiwalencja pojęć odnoszących się do systemów osadniczych i społecznych}

Czy systemy osadnicze w języku oryginału i w języku grupy docelowej odpowiadają sobie i jaka jest ta grupa docelowa?

Porównywanie pojęć odnoszących się do systemów osadniczych nastręcza problemów nawet współcześnie w ramach niezwykle sformalizowanych struktur Unii Europejskiej. Za monitorowanie i raportowanie w kwestiach ekonomicznych

\footnotetext{
22 Zob. M. Carrara, P. Giaretta, The Many Facets of Identity Criteria, „Dialectica”, 58 (2), 2004; P. Hallot, R. Billen, Enhancing Spatio-Temporal Identity. States of Existence and Presence, „ISPRS International Journal of Geo-Information", 5 (5), 2016; F. Gantner i in., The Basic Formal Ontology as a Reference Framework for Modeling the Evolution of Administrative Units, „Transactions in GIS”, 17 (2), 2013.

${ }^{23}$ T. Abraham, Roddick J.F., Survey of Spatio-Temporal Databases, , Geolnformatica", 3 (1), 1999; I. Gregory, Time-variant GIS Databases of Changing Historical Administrative Boundaries. A European Comaprison, „Transactions in GIS", 6 (2), 2002; E. Hyvonen i in., Representing and Utilizing Changing Historical Places as an Ontology Timeseries, w: Geospatial Semantics and the Semantic Web. Foundations, Algorithms, and Applications, ed. N. Ashish, A.P. Sheth, New York 2011 (Semantic Web and Beyond).

${ }^{24}$ P. Garbacz, A. Ławrynowicz, B. Szady, Identity Criteria for Localities, w: Formal Ontology in Information Systems, ed. S. Borgo, P. Hitzler, 0. Kutz, Amsterdam 2018, s. 47.

${ }^{25}$ Tamże, s. 51-53.
} 
i społecznych w ramach UE odpowiada Eurostat, który operuje jednostkami (polami bazowymi) NUTS (fr. Nomenclature des Unités territoriales statistiques). W przybliżeniu NUTS 1 odpowiada krajom czy też makroregionom, NUTS 2 regionom, NUTS 3 podregionom, a następnie, $w$ razie potrzeby wprowadzana jest pomocnicza jednostka LAU (ang. local administrative unit). Przypisanie jednostek terytorialnych do poszczególnych poziomów klasyfikacji uzależnione jest od uwarunkowań podziału administracyjnego, a także uwarunkowań geograficznych, historycznych i innych poszczególnych krajów. Dla przykładu: NUTS 1 w Polsce odpowiada całemu krajowi, a w Niemczech poszczególnym landom. Największy obszar w tej kategorii ma aż 336830 km (Manner-Suomi w Finlandii), najmniejszy 316 i jest to cała $\mathrm{Malta}^{26}$, a np. Luxemburg pojawia się we wszystkich trzech kategoriach NUTS jako cały obszar. Jeśli współczesne podziały okazują się tak trudne do ujednolicenia, to historyczne systemy administracji są jeszcze trudniejsze do zakomunikowania poza kulturą, w której funkcjonowały.

Przykład 1: powiat - rozważanie nad grupą docelową

Pierwszy przykład posłuży nam za przyczynek do dyskusji nad grupą docelową tłumaczenia i nad jej znaczeniem w kontekście pojęć mających wymiar przestrzenny. Załóżmy, że tekst naukowy ma zostać opublikowany po angielsku, wybieramy wariant brytyjski, ale chcemy zakomunikować wyniki naszej pracy międzynarodowej społeczności naukowców. Już w samym Zjednoczonym Królestwie mamy cztery oddzielne systemy podziału terytorialnego (angielski, irlandzki, szkocki i walijski). Jeśli zdecydujemy się na strategię domestykacji, mamy dwie możliwości tłumaczenia: county, którego odpowiednikiem

\footnotetext{
${ }^{26}$ Eurostat, Statistical Regions in the European Union and Partner Countries, Luxemburg; Eurostat, Applying the Degree of Urbanisation - A Methodological Manual to Define Cities, Towns and Rural Areas for International Comparisons, 2021
}

pod względem rozmiaru, poziomu podziału administracyjnego i funkcjonowania jest powiat, oraz district, który jednak w samym Zjednoczonym Królestwie jest jednostką mniejszą. District jest również wyborem, który można uzasadniać częściowym obraniem strategii egzotyzacji, ponieważ na obszarze Rzeczypospolitej powiat funkcjonował również jako łaciński districtus. Pozostaje zatem pytanie, czy jeżeli łacina była lingua franca Europy przednowoczesnej, to posługiwanie się pojęciem district jest domestykacją czy egzotyzacją oraz, nawiązując do metod tłumaczenia przytoczonych powyżej, czy jest to strategia wymiany, czy tłumaczenia.

Teoria skoposu również dostarcza argumentów za wyborem słowa district jako odpowiednika dla polskiego powiatu - naszą grupą docelową odbiorców jest społeczność historyków, a więc grupa w swej większości posługująca się łaciną, co podniesie zrozumiałość terminu district użytego w miejsce powiatu.

Przykład 2: wójt i wójtostwo - rozważanie nad lokalną specyfiką jednostek

Według Stefana Sochaniewicza wójtostwa są skutkiem lokowania miejscowości na prawie niemieckim: nadawanie przywileju było prerogatywą króla, a zarządzający nim wójt był reprezentantem władcy feudalnego, czyli administracji centralnej ${ }^{27}$. Taki sposób lokacji miast na podstawie przywileju jest charakterystyczny m.in. dla terenów Rzeczypospolitej w średniowieczu i nowożytności. Tłumacząc pojęcie „wójt”, możemy przyjąć strategię domestykacji, posługując się niemieckim odpowiednikiem Vogt, albo pozostawić słowo w jego oryginalnym brzmieniu. W celu oddania specyfiki tej jednostki, przy pierwszym pojawieniu się słowa wójt/wójtostwo warto posłużyć się objaśnieniem, przypisem bądź też notą translatorską.

\footnotetext{
${ }^{27}$ S. Sochaniewicz, Wójtostwa i sołtystwa pod względem prawnym i ekonomicznym w ziemi Iwowskiej, Lwów 1921.
} 
Przykład 3: gospodarka folwarczna - rozważania nad strukturami społecznymi

Gspodarka folwarczna mogłaby nam posłużyć za przykład specyficznej organizacji administracyjnej bądź systemu społecznego w skali organizacji kraju. Układ, w którym chłop pańszczyźniany, niebędący ani angielskim serf, ani villein, ani zwykłym peasant, część swojego czasu wkładat $\mathrm{w}$ pracę $\mathrm{w}$ gospodarstwie szlachcica bądź innego włodarza ziemskiego, był specyficzny dla Rzeczypospolitej. Dodatkowo na całość społeczności wiejskiej składają się również różne grupy szlachty, w tym szlachta zagrodowa (sama uprawiająca rolę) i drobna szlachta folwarczna. Każde województwo, a nawet region, miały inną charakterystykę relacji społecznych. Przyjrzyjmy się zatem pojęciu folwark, które zwykle tłumaczone jest jako manor. W rzeczywistości to, co ogólnie nazywamy folwarkiem w języku polskim, w języku angielskim ma dwa odpowiedniki: manor house $^{28}$ - czyli sama posiadłość $\mathrm{z}$ dworem, oraz manor demesne $e^{29}$. Jest to przykład rozbieżności w ekwiwalencji konotacyjnej i denotacyjnej, bo to, co denotuje polskie słowo folwark, jest w języku angielskim realizowane przez słowo manor $\mathrm{z}$ dwoma różnymi określeniami, a konotacje, jakie ze sobą niosą te określenia są różne od konotacji słowa polskiego. Skutkuje to również problemem z zachowaniem spójności informacji w całym tekście, aby czytelnik miał podobny obraz całego systemu społecznego, jak czytelnik tekstu w oryginale.

\section{Zmienność pojęcia w przestrzeni}

W tej części rozważymy istnienie lub też różne rozumienie tych samych pojęć w zależności od przestrzeni geograficznej, do której się odnosimy. Jak zauważyliśmy na przykładzie powiatu, pewne kategorie mogą nie występować w systemie pojęć

\footnotetext{
${ }^{28} \mathrm{https} / / /$ www.merriam-webster.com/dictionary/manor, dostęp: 10 kwietnia 2021.

${ }^{29} \mathrm{https}: / /$ www.merriam-webster.com/dictionary/demesne, dostęp: $10 \mathrm{kwietnia}$ 2021.
}

języka docelowego, mogą istnieć tylko w pewnych obszarach, albo być różnie rozumiane $\mathrm{w}$ zależności od położenia geograficznego.

Przykład 4: kmieć, komornik i zagrodnik Piotr Guzowski ${ }^{30}$ wśród mieszkańców wsi wyróżnia rodziny kmiece, zagrodnicze i komornicze. Te pierwsze w zależności od regionu liczyły nawet od ośmiu do dziesięciu osób ${ }^{31}$. Zagrodnicy (łac. hortulani), to rodziny liczące zazwyczaj około pięciu osób i posiadające jedynie skrawek gruntu wokół zagrody, gdzie zwykle uprawiali ogród warzywny (lat. hortus) ${ }^{32}$. Komornikami określa się chłopów mieszkających wraz z rodziną u innego chłopa (niem. Kammerleute). Nie wszystkie te grupy znajdują swoje odzwierciedlenie $\mathrm{w}$ innych społeczeństwach nowożytnej Europy. Przykładowo, poszukując ekwiwalentów, znajdujemy dla komornika szkockiego cotter, a dla zagrodnika smallholder ${ }^{33}$. W obu przypadkach jednak konotacje tych słów są odmienne od oryginału. Czy powinniśmy zatem posłużyć się strategią egzotyzacji i pozostawić polskie terminy "komornik” i „zagrodnik”, opatrując je notą edytorską, odwołać się do niemieckiego i łaciny, jako języków bardziej rozpowszechnionych, czy może wyjaśnić te pojęcia przy pierwszym użyciu? Ponadto, angielskie smallholder jest pojęciem używanym obecnie na małe farmy produkujące na swoje potrzeby, co prowadzi nas do następnej kwestii, czyli jak dane pojęcie funkcjonowało i było rozumiane w różnych momentach historii.

\footnotetext{
${ }^{30}$ P. Guzowski, The Present State and Prospects of Research on the Size of Poland's Population in the Late Middle Ages and at the Beginning of Early Modern Times, „Przeszłość Demograficzna Polski”, 37, 2015.

${ }^{31}$ P. Guzowski, Badania demograficzne nad rodziną wiejską w okresie staropolskim, w: Struktury demograficzne rodziny na ziemiach polskich do połowy XX wieku. Przegląd badań i problemów, red. P. Guzowski, C. Kukla, Białystok 2014, s. 26.

${ }^{32}$ Tamże; Prusy Królewskie w drugiej połowie XVI wieku, oprac. M. Biskup przy współudziale L. Koca, Warszawa 1961 (Atlas Historyczny Polski. Seria $B$, Mapy przeglądowe 1).

${ }^{33}$ https://www.merriam-webster.com/dictionary/smallholding, dostęp: 10 kwietnia 2021.
} 


\section{Zmienność pojęcia w czasie}

Przykład 5: miasto i miasteczko

W języku polskim funkcjonują słowa "miasto" i „miasteczko" i analogicznie język angielski oferuje dwa terminy: town i city. Internetowy słownik Merriam-Webster definiuje city jako zamieszkany obszar o większych rozmiarach i populacji niż town ${ }^{34}$. Jednak jeśli przyjrzymy się publikacjom na temat miast ery przedindustrialnej, a więc takich jak Toruń w Polsce ${ }^{35}$ i Winchester, York czy Londyn w Wielkiej Brytanii wydanych w serii wydawniczej Historic Towns Atlas ${ }^{36}$ okazuje się, że autorzy posługują się słowem town dla miast założonych przed erą industrialną, a słowem city dla miast od początku ery industrialnej do teraz. Pozwala to na uniknięcie niepotrzebnego anachronizmu. Nie jest to jednak jedyne rozróżnienie, które musi wziąć pod uwagę tłumacz, zajmując się pojęciem miasta, gdyż z prawnego punktu widzenia status city nadawany jest często prawnie lub wynika z uwarunkowań historycznych konkretnych jednostek. Wróćmy do Zjednoczonego Królestwa, gdzie już w V w. naszej ery Gildas przywołuje 28 miast $^{37}$ (cities, z łacińskiego civitas), a prawny status miast wynika obecnie $\mathrm{z}$ nadanych przywilejów (ang. charter i letters patent). Tłumacz musi zatem podjąć decyzję, czy odnosi się do pojęcia miasta systemowo w kategoriach historycznych (city i town jako miasta ery nowoczesnej i przednowoczesnej), w kategoriach rozmiaru, czy jednostkowo w zależności od uwarunkowań, np. poszukując paralelnych procesów nadania praw miejskich. Podjąwszy taką

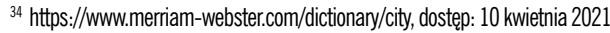

${ }^{35}$ W. Duży, City through Empires. Toruń (Poland) in an Ontology of Historical Geographic Information Systems from the 10th to 20th Centuries, w: Proceedings of the Digital Humanities Congress 2018, ed. L. Pitcher, M. Pidd, Sheffield 2018.

${ }^{36}$ British Historic Towns Atlas. Winchester, ed. M. Biddle i in., Oxford 2017 (British Historic Towns Atlas, 6); The City of London from prehistoric times to c.1520, ed. M.D. Lobel, New York 1989 (British Historic Towns Atlas, 3); D. Bruce, 0. Creighton, Town Walls and Walled Towns. A Contested Heritage, „International Journal of Heritage Studies”, 12 (3), 2006.

${ }^{37}$ Giles J.A., Gildas, Cambridge, Ontario 2000.
}

decyzję, tłumacz również musi wziąć pod uwagę różne pola semantyczne wybranych terminów, np. zwracając uwagę na różne konotacje słów „miasteczko” i small town, często w kontekście pejoratywnym, np. „małomiasteczkowy”, „mieścina”.

\section{Przykład 6: województwo}

Ostatnim przykładem łączącym w sobie wszystkie trzy wyżej wymienione kategorie, jest województwo. Z punktu widzenia systemów podziału administracyjnego możemy posłużyć się strategią domestykacji, oferując najbliższy denotacyjnie ekwiwalent - province albo county (według podziału Kathariny Reiss i Hansa Vermeera), albo możemy zastosować strategię egzotyzacji i pozostać przy voivodeship. Warto również pamiętać, że ze względu na rozległość ziem Korony województwa miały różne powierzchnie, np. pomorskie $12907 \mathrm{~km}^{238}$ czy malborskie $2096 \mathrm{~km}^{239}$. Warto zatem, wprowadzając ten termin, dodać notę od autora i tłumacza, która pomoże czytelnikowi zrozumieć specyfikę systemu. Ostatni czynnik wpływający na nasze decyzje, to zmienność terminu w czasie. Odwołując się do przykładu rozróżnienia pomiędzy town i city oraz mając na uwadze fakt wspomniany przy omawianiu powiatu, że łacina była językiem nauki i administracji w całej nowożytnej Europie, warto zaproponować użycie słowa palatinate $^{40}$ jako ekwiwalent pozwalający uniknąć anachronizmu.

\section{Propozycja rozwiązania}

Problem różnego rozumienia pojęć geograficznych nie dotyczy tylko kwestii tłumaczeń. Niektóre terminy, takie jak „,entrum” czy „peryferia” są względne i trudne do zdefiniowania ${ }^{41}$. Chciałabym zatem spróbować zaproponować rozwiązanie problemów

\footnotetext{
${ }^{38}$ Prusy Królewskie w drugiej połowie XVI wieku, s. 31

${ }^{39}$ Tamże, s. 30.

${ }^{40} \mathrm{https} / / /$ www.Idoceonline.com/dictionary/palatinate, dostęp: 10 kwietnia 2021.

${ }^{41}$ A.J. Evans, T. Waters, Mapping Vernacular Geography. Web-based GIS Tools for Capturing „Fuzzy” or "Vague” Entities, „International Journal of Technology, Policy and Management", 7 (2), 2008.
} 
omówionych powyżej przez schematyczne nakreślenie ram dla opracowania słownika pojęć historyczno-geograficznych w oparciu o trzy omówione powyżej aspekty: przystawanie systemów i kategorii oraz zmienność terminu w czasie i w przestrzeni. Dla pojęć opisanych powyżej rozważę po dwa (trzy w przypadku województwa) ekwiwalenty, których precyzyjność i nakładanie się (ang. overlap) można przedstawić za pomocą uwag ogólnych, pozytywnych (oznaczonych plusem „„”) oraz negatywnych aspektów („,-") poszczególnych propozycji (tabela 1). Następnie każdą z kategorii oceniamy w ciągłej skali od 0 do 1.

Wykonałam taką przykładową ocenę dla terminu „powiat”. W kontekście tłumaczenia tekstów dotyczących okresu staropolskiego słowo district wydaje się być bardziej odpowiednim ekwiwalentem, ponieważ bierze pod uwagę potencjalną grupę odbiorców tekstu, czyli osoby zajmujące się historią Europy. Mają one zwykle w swoim warsztacie znajomość łaciny, która pozwala im korzystać ze źródeł historycznych. Ponadto słowo district dalej funkcjonuje w języku angielskim, więc pozwala na zachowanie spójności systemu informacji na poziomie całego tekstu. Aby uniknąć ryzyka redukcjonistycznego podejścia do oceny poszczególnych potencjalnych ekwiwalentów, czyli rozważań, czy należy wpisać 0,7 , czy 0,8 , powinna się ona odbywać np. za pomocą suwaków opatrzonych pytaniem (np.: czy systemy pojęć/kategorii sobie odpowiadają?) wraz z wyświetlaną listą uwag, jak w tabeli poniżej. Ocena ta, chociaż oparta o listę przytoczonych cech, jest arbitralna i dlatego postuluję, aby tak zaprojektowany słownik podlegał ciągłej weryfikacji przez środowisko specjalistów z dziedziny. Tego typu rozwiązania, oparte o uczestnictwo szerszej społeczności, sprawdzają się w sytuacjach, gdy jednoznaczne określenie słuszności jest niemożliwe, jak np. w humanistyce, gdy potrzebne jest unikalne podejście do danych i ich prezentacja $^{42}$. Pole „Ocena średnia” podaje sugerowany najodpowiedniejszy ekwiwalent. Oczywiście należy również pamiętać, że ostateczny wybór tłumaczenia będzie również zależał od obranej przez tłumacza strategii i grupy odbiorców tekstu w języku docelowym.

\section{Dyskusja}

Problem nieprzekładalności nie dotyczy jedynie tekstów z dziedziny historii i geografii. O rozbieżności systemów, która manifestuje się w języku, piszą prawnicy ${ }^{43}$, antropolodzy ${ }^{44}$, etnografowie ${ }^{45}$ i oczywiście językoznawcy ${ }^{46}$ analizujący różnice między językami w ramach językoznawstwa kontrastywnego ${ }^{47}$ lub poszukujący wspólnego mianownika dla wielu kultur i języków ${ }^{48}$, podobnie jak to miało miejsce $\mathrm{w}$ powyższym tekście. Możemy się zatem zastanowić, jak powyższe rozważania i propozycje, np. dla słowa "miasto”, były realizowane w tekstach na temat historii Europy przednowoczesnej. W ramach serii wydawniczej Historic Towns

\footnotetext{
${ }^{42}$ Tamże; T.M. Harris, From PGIS to Participatory Deep Mapping and Spatial Storytelling. An Evolving Trajectory in Community Knowledge Representation in GIS, „The Cartographic Journal”, 53 (4), 2016; J. Pánek, Emotional Maps. Participatory Crowdsourcing of Citizens' Perceptions of Their Urban Environment, „Cartographic Perspectives”, 91, 2019, s. 17-29.

${ }^{43}$ N.E. Bobrova, A.V. Lebedev, I.S. Pinkovetskaia, Peculiarities of the English Legal Text Discourse. The Issues of Interpretation and Translatability, „Journal of History Culture and Art Research”, 9 (2), 2020; S. Goźdź-Roszkowski, The Role of Generic Competence and Professional Expertise in Legal Translation. The Case of English and Polish Probate Documents, „Studies in Logic, Grammar and Rhetoric", 45 (1), 2016; M. Farrokhi, The Role of Legal Translation in the Interpretation of International Law Documents, „Russian Law Journal”, 7 (1), 2019.

${ }^{44}$ E. Hayman, M. Wedge, C. James, A Deep Chart (the Aqua-Face of Deep Mapping), „International Journal of Humanities and Arts Computing”, 11 (1), 2017.

${ }^{45} \mathrm{~S}$. Stano, Eating the Other. A Semiotic Approach to the Translation of the Culinary Code, Newcastle upon Tyne 2015.

${ }^{46}$ B. Rudzka-Ostyn, Word Power. Phrasal Verbs and Compounds. A Cognitive Approach, Berlin 2003 (Planet Communication); Conceptualizations and Mental Processing in Language, ed. R.A. Geiger, B. Rudzka-0styn, New York 1993

${ }^{47}$ S. Marzo, K. Heylen, G. de Sutter, Corpus Studies in Contrastive Linguistics, Amsterdam 2012 (Benjamins Current Topics, 43).

${ }^{48}$ A. Wierzbicka, Semantics. Primes and Universals, Oxford 1996; Semantic and Lexical Universals, ed. C. Goddard, A. Wierzbicka, Amsterdam-Philadelphia 1994 (Studies in Language Companion Series, 25); A. Wierzbicka, Understanding Cultures Through Their Key Words. English, Russian, Polish, German, and Japanese, New York 1997.
} 
Tabela 1. Tłumaczenie terminów geograficzno-historycznych w oparciu o trzy pytania

\begin{tabular}{|c|c|c|c|c|c|}
\hline \multirow{2}{*}{$\begin{array}{l}\text { Numer } \\
\text { przykładu }\end{array}$} & \multirow{2}{*}{ Pojęcie } & \multirow{2}{*}{ Język } & \multirow{2}{*}{$\begin{array}{l}\text { Propozycja } \\
\text { pojęcia }\end{array}$} & \multicolumn{2}{|l|}{ 1. Czy systemy pojęć/kategorii sobie odpowiadają? } \\
\hline & & & & Cechy & Ocena \\
\hline \multirow{2}{*}{1} & \multirow{2}{*}{ powiat } & EN & district & $\begin{array}{l}\text { + dla społeczności posługującej się łacina } \\
\text { + pojęcie istnieje, lub istniało powszechnie } \\
\text { - obecnie denotuje również dzielnice } \\
\text { - dla Zjednoczonego Królestwa (UK) - różne systemy administracyjne }\end{array}$ & 0,8 \\
\hline & & EN & county & $\begin{array}{l}\text { + zrozumiały dla mieszkańców UK } \\
\text { - nie jest terminem uniwersalnym, tylko nacechowanym specyfiką UK }\end{array}$ & 0,6 \\
\hline \multirow{2}{*}{2} & \multirow{2}{*}{ wójt } & EN & wójt & $\begin{array}{l}\text { + zachowuje wszystkie cechy i konotacje (strategia egzotyzacji) } \\
\text { - wymaga noty od tłumacza } \\
\text { - nie występuje w systemie pojęć języka docelowego }\end{array}$ & \\
\hline & & EN & Vogt & $\begin{array}{l}\text { + pojęcie związane z językiem oryginału (systemowo i nazewniczo) } \\
\text { + funkcjonuje w zachodnim kręgu kulturowym } \\
\text { - obce dla użytkownika języka angielskiego } \\
\text { - wymaga noty od tłumacza }\end{array}$ & \\
\hline \multirow[b]{2}{*}{3} & \multirow[b]{2}{*}{ folwark } & EN & manor & $\begin{array}{l}\text { + manor odpowiada pojęciu folwark w znaczeniu ogólnym } \\
\text { - gdy posługujemy się folwarkiem w znaczeniu ośrodka rolno-przemysłowego } \\
\text { angielski wymaga bardziej szczegółowego rozróżnienia }\end{array}$ & \\
\hline & & EN & $\begin{array}{l}\text { manor housel } \\
\text { manor } \\
\text { demesne }\end{array}$ & $\begin{array}{l}\text { + bardziej szczegółowe rozróżnienie naturalnie występujace w języku } \\
\text { angielskim } \\
\text { - manor house odpowiada posiadłości z dworem, znaczy również sam } \\
\text { „dworek” } \\
\text { - manor demesne odpowiada całej posiadłości i jest używane jako ekwiwalent } \\
\text { folwarku w znaczeniu ośrodka rolno-przemysłowego }\end{array}$ & \\
\hline \multirow{2}{*}{$4 a$} & \multirow{2}{*}{ zagrodnik } & EN & hortulan(us/i) & $\begin{array}{l}\text { - słowo obce dla przeciętnego użytkownika języka angielskiego } \\
\text { + język pochodzenia terminu to łacina - odwołanie się do kategorii znanych } \\
\text { odbiorcom tekstów z dziedziny historii } \\
\text { + w powszechnym użyciu w Europie (połączenie strategii domestykacji } \\
\text { i egzotyzacji) }\end{array}$ & \\
\hline & & EN & smallholder & $\begin{array}{l}\text { + w użyciu we współczesnym języku } \\
\text { - pojęcie szersze, również obejmujące małe famy } \\
\text { - jeśli tlumacz zdecyduje się użyć również słowa cotter na komornika, użycie } \\
\text { smallholder na zagrodnika pozwala na zachowanie spójności struktury } \\
\text { informacji w całym tekście }\end{array}$ & \\
\hline \multirow[b]{2}{*}{$4 b$} & \multirow[b]{2}{*}{ komornik } & EN & Kammerleute & $\begin{array}{l}\text { - pojęcie obce użytkownikowi języka angielskiego } \\
\text { - wymaga noty od tłumacza }\end{array}$ & \\
\hline & & EN & cotter & $\begin{array}{l}\text { + odwołuje się do podobnego źródłosłowu (komornik - mieszkający } \\
\text { w komorze, cotter - mieszkajacy w chacie) } \\
\text { - wymaga noty od tłumacza }\end{array}$ & \\
\hline \multirow[b]{2}{*}{5} & \multirow[b]{2}{*}{ miasto } & EN & town & - rozróżnienie na miasto i miasteczko a angielskie city i town nie są tożsame & \\
\hline & & EN & city & - rozróżnienie na miasto i miasteczko a angielskie city i town nie są tożsame & \\
\hline
\end{tabular}




\begin{tabular}{|c|c|c|c|c|}
\hline 2. Jak zmienny/różny jest termin przestrzennie? & & \multicolumn{2}{|l|}{ 3. Jak termin ewoluował? } & \multirow{2}{*}{ Średnia } \\
\hline Cechy & Ocena & Cechy & Ocena & \\
\hline $\begin{array}{l}\text { - duża zmienność w zależności od województwa } \\
\text { (w języku oryginału) } \\
\text { + podobna zmienność w różnych krajach Europy }\end{array}$ & 0,7 & $\begin{array}{l}\text { + obecnie również używany jako ekwiwalent powiatu } \\
\text { - współcześnie również używany w znaczeniu } \\
\text { „dzielnica” }\end{array}$ & 0,6 & 0,70 \\
\hline $\begin{array}{l}\text { - duża zmienność w zależności od województwa } \\
\text { (w języku oryginału) } \\
\text { + podobna zmienność w różnych krajach Europy }\end{array}$ & 0,7 & $\begin{array}{l}\text { - obecnie denotuje współczesne jednostki podziału } \\
\text { administracyjnego i statystycznego w UK }\end{array}$ & 0,5 & 0,60 \\
\hline duża różnorodność - zależały od konkretnego nadania & & $\begin{array}{l}\text { + termin dalej używany w języku polskim } \\
\text { - polski termin obecnie denotuje urzędnika, organ } \\
\text { wykonawczy w gminie, wybieranego w wyborach } \\
\text { samorządowych }\end{array}$ & & \\
\hline duża różnorodność - zależały od konkretnego nadania & & $\begin{array}{l}\text { - polski termin obecnie denotuje urzędnika, organ } \\
\text { wykonawczy w gminie, wybieranego w wyborach } \\
\text { samorządowych }\end{array}$ & & \\
\hline $\begin{array}{l}\text { + zarówno pojęcie oryginalne i ekwiwalent wywodzą się } \\
\text { z systemu feudalnego }\end{array}$ & & $\begin{array}{l}\text { British National Corpus podaje nast. kolokacje dla } \\
\text { słowa manor: house(s), lord(s), ground(s), ale obecnie } \\
\text { hotel, co oznacza, że obecnie słowo manor pojawia } \\
\text { się w kontekście dworów zaadaptowanych na potrzeby } \\
\text { usług hotelowych }\end{array}$ & & \\
\hline $\begin{array}{l}\text { - pojęcie oryginalne i ekwiwalent wywodzą się z systemu } \\
\text { feudalnego } \\
\text { + różne cechy folwarku i manor, np. Manor houses } \\
\text { bywały umocnione, co przemawia za rozróżnieniem }\end{array}$ & & $\begin{array}{l}\text { British National Corpus podaje nast. kolokacje dla } \\
\text { słowa manor. house(s), lord(s), ground(s), ale obecnie } \\
\text { hotel, co oznacza, że obecnie słowo manor pojawia } \\
\text { się w kontekście dworów zaadaptowanych na potrzeby } \\
\text { usług hotelowych }\end{array}$ & & \\
\hline $\begin{array}{l}\text { + pojęcie charakterystyczne dla Rzeczypospolitej } \\
\text { (specyficzna stratyfikacja społeczna) }\end{array}$ & & $\begin{array}{l}\text { + termin w użyciu w Europie, w tym w Rzeczypospolitej } \\
\text { przednowoczesnej } \\
\text { - brak współczesnych konotacji }\end{array}$ & & \\
\hline $\begin{array}{l}\text { + znaczenie zmienia się w zależności od miejsca } \\
\text { + odwołuje się do kategorii lokalnych (posiadanie małej } \\
\text { farmy - względność) } \\
\text { - wymaga noty od tłumacza }\end{array}$ & & $\begin{array}{l}\text { - kategoria skali własności (małe farmy), inne konotacje, } \\
\text { chociaż bliskoznaczne } \\
\text { + dalej denotuje rolnika z małym areałem } \\
\text { produkującego na własne potrzeby }\end{array}$ & & \\
\hline $\begin{array}{l}\text { - pojęcie używane w części terenów Rzeczypospolitej } \\
\text { (np. Prusy Książęce) }\end{array}$ & & - brak we współczesnym użyciu & & \\
\hline + pojęcie charakterystyczne dla terenów Szkocji & & $\begin{array}{l}\text { - brak we współczesnym użyciu } \\
\text { + obecnie również denotuje nazwy własne (miasto, } \\
\text { rzeka) }\end{array}$ & & \\
\hline $\begin{array}{l}\text { rozróżnienie czym jest city i town czyli czym jest duże } \\
\text { i małe miasto zależy od kraju i regionu (por. miasto } \\
\text { w Polsce i w Chinach) }\end{array}$ & & $\begin{array}{l}\text { + termin używany do określania miast powstałych przed } \\
\text { industrializacja } \\
\text { + w UK miasto bez statusu city }\end{array}$ & & \\
\hline $\begin{array}{l}\text { rozróżnienie czym jest city i town czyli czym jest duże } \\
\text { i małe miasto zależy od kraju i regionu (por. miasto } \\
\text { w Polsce i w Chinach) }\end{array}$ & & $\begin{array}{l}\text { + termin używany do określania miast powstałych przed } \\
\text { industrializacją } \\
\text { + historycznie status city wiązał się z pochodzeniem } \\
\text { (miasta rzymskie) lub statusem nadanym na mocy } \\
\text { przywileju }\end{array}$ & & \\
\hline
\end{tabular}


Tabela 1. cd.

\begin{tabular}{|c|c|c|c|c|c|}
\hline \multirow{2}{*}{$\begin{array}{c}\text { Numer } \\
\text { przykładu }\end{array}$} & \multirow{2}{*}{ Pojęcie } & \multirow{2}{*}{ Język } & \multirow{2}{*}{$\begin{array}{l}\text { Propozycja } \\
\text { pojęcia }\end{array}$} & \multicolumn{2}{|l|}{ 1. Czy systemy pojęć/kategorii sobie odpowiadają? } \\
\hline & & & & Cechy & Ocena \\
\hline \multirow{3}{*}{6} & województwo & EN & palatinate & $\begin{array}{l}\text { + odwołanie się do łaciny (wspólnej dla całej Europy przednowoczesnej) } \\
\text { (połączenie strategii domestykacji i egzotyzacji) } \\
\text { + język znany osobom zajmującym się historią Europy }\end{array}$ & \\
\hline & województwo & EN & province & + odwołanie się do kategorii z języka docelowego (strategia domestykacji) & \\
\hline & województwo & EN & voivodeship & + odwołanie się do kategorii z języka oryginału (strategia egzotyzacji) & \\
\hline
\end{tabular}

Atlas ukazało się ponad pięćset atlasów i publikacji o miastach, w tym na temat osiemnastu miast w Polsce. Inicjatywa ta, zawiązana już w 1955 r., obrała rozróżnienie town/city zgodnie $\mathrm{z}$ czasem powstania miasta, czyli słowo town opisuje również takie wielkie miasta jak Londyn, Wiedeń czy Praga ${ }^{49}$. Podobną praktykę można znaleźć w innych publikacjach o rozwoju miast ${ }^{50}$. Inni autorzy posługują się tym rozróżnieniem w odniesieniu do rozmiaru miasta $^{51}$. To drugie podejście jest również reprezentowane przez angielskie wydanie Altasu Historycznego ${ }^{52}$ oraz w publikacjach o miastach średniowiecznych ${ }^{53} \mathrm{czy}$ o rozwoju handlu i urbanizacji ${ }^{54}$. Prowadzi to ponownie do wniosku, że decyzje o doborze właściwego ekwiwalentu zależą od

\footnotetext{
${ }^{49} \mathrm{http}: / /$ www.uni-muenster.de/Staedtegeschichte/en/portal/staedteatlanten/ historictownsatlasesforum.html, dostep: 10 kwietnia 2021.

${ }^{50}$ H. Swanson, Medieval British Towns, London 1999; R. Holt, G. Rosser, The English Medieval Town. A Reader in English Urban History 1200-1540, London 1990.

${ }^{51}$ P. Clark, European Cities and Towns: 400-2000, 0xford-New York 2009; C.D. Liddy, Contesting the City. The Politics of Citizenship in English Towns, 1250-1530, 0xford-New York 2017 (Oxford studies in medieval European history); B. Kümin, The Communal Age in Western Europe, c.1100-1800. Towns, Villages and Parishes in Pre-modern Society, Basingstoke 2013.

${ }^{52}$ Historical Atlas of Poland in the 2nd Half of the 16th Century. Voivodeships of Cracow, Sandomierz, Lublin, Sieradz, tęczyca, Rawa, Ptock and Mazovia, ed. M. Słoń, Frankfurt am Main 2014 (Geschichte - Erinnerung - Politik. Studies in History, Memory and Politics).

${ }^{53} \mathrm{~J}$. Macháček, The Rise of Medieval Towns and States in East Central Europe. Early Medieval Centres as Social and Economic Systems, Leiden-Boston 2010 (East Central and Eastern Europe in the Middle Ages, 450-1450, 10).

${ }^{54}$ F.W. Cater, Trade and Urban Development in Poland an Economic Geography of Cracow, from its Origins to 1795, Cambridge 1994; L. Benevolo, The Origins of Modern Town Planning, Massachusetts 1963.
}

celu i strategii tłumacza, więc wymagają całościowego przeanalizowania, w czym pomocne może być rozwiązanie zaproponowane w niniejszym artykule.

\section{Podsumowanie}

W obliczu dylematu nieprzekładalności kulturowej tłumacz i autor mają za zadanie wybranie optymalnej strategii doboru terminów i pojęć, tak aby pomóc odbiorcy tekstu możliwie najlepiej zrozumieć treści oryginału. Każda z podjętych decyzji będzie podyktowana wieloma czynnikami. Mogą one wynikać z potrzeby przybliżenia systemu oryginału (strategia egzotyzacji) lub odwołania się do systemu kategorii bliższego odbiorcy (strategia domestykacji) i wiążą się bezpośrednio z grupą docelową tekstu tłumaczenia, jej charakterem, zakresem wiedzy, jaką posiada, celem wykorzystania tekstu. Czynniki te można sprowadzić do trzech głównych pytań o: spójność systemów, którymi się posługujemy (np. czy podziały administracyjne sobie odpowiadaja), o zmienność tych systemów, a co za tym idzie pojęć, w przestrzeni (np. czy ten sam termin podobnie rozumiany jest różnych krajach i regionach) oraz o ich zróżnicowanie w czasie (np. jak ewoluował i był rozumiany w różnych okresach). W tekście zaproponowana została metoda rozważań różnych propozycji tłumaczeń pojęć związanych z przestrzenią, która uwzględnia te trzy kwestie i pozwala na ich 


\begin{tabular}{|c|c|c|c|c|}
\hline 2. Jak zmienny/różny jest termin przestrzennie? & & \multicolumn{2}{|l|}{ 3. Jak termin ewoluował? } & \multirow{2}{*}{ Średnia } \\
\hline Cechy & Ocena & Cechy & Ocena & \\
\hline $\begin{array}{l}\text { - duża zmienność w zależności od regionu (w języku } \\
\text { oryginału) } \\
\text { + podobnie duża zmienność w różnych krajach Europy }\end{array}$ & & + pozwala uniknąć anachronizmu & & \\
\hline $\begin{array}{l}\text { - znaczenie słowa province w języku angielskim zależy } \\
\text { od miejsca pochodzenia czytelnika }\end{array}$ & & $\begin{array}{l}\text { + termin obecnie używany, niekoniecznie jako } \\
\text { ekwiwalent słowa „województwo" }\end{array}$ & & \\
\hline $\begin{array}{l}\text { - duża różnorodność województw w Rzeczypospolitej } \\
\text { w zależności od regionu i okresu }\end{array}$ & & $\begin{array}{l}\text { + wielkość i znaczenie (w tym administracyjne) słowa } \\
\text { województwo zmieniało się wraz z reformami i zmianami } \\
\text { administracyjnymi w Polsce }\end{array}$ & & \\
\hline
\end{tabular}

szczegółową analizę oraz wybór pomiędzy różnymi wariantami na podstawie wielu uwag i komentarzy oraz subiektywnej oceny ,ekwiwalencji” tych propozycji.

\section{Bibliografia}

Abraham T., Roddick J.F., Survey of Spatio-Temporal Databases, „GeoInformatica”, 3 (1), 1999, s. 61-99.

Baker M., In Other Words. A Coursebook on Translation, Abingdon Oxon 2006.

Baker M., Translation and Conflict. A Narrative Account, London 2006.

Benevolo L., The Origins of Modern Town Planning, Massachusetts 1963.

Bobrova N.E., Lebedev A.V., Pinkovetskaia I.S., Peculiarities of the English Legal Text Discourse. The Issues of Interpretation and Translatability, ,Journal of History Culture and Art Research", 9 (2), 2020, s. 318.

British Historic Towns Atlas. Winchester, ed. M. Biddle $\mathrm{i}$ in., Oxford 2017 (British Historic Towns Atlas, 6).

Bruce D., Creighton O., Town Walls and Walled Towns. A Contested Heritage, „International Journal of Heritage Studies”, 12 (3), 2006, s. 1-20.

Carrara M., Giaretta P., The Many Facets of Identity Criteria, „Dialectica”, 58 (2), 2004, s. 221-232.

Cater F.W., Trade and Urban Development in Poland an Economic Geography of Cracow, from its Origins to 1795, Cambridge 1994.

Clark P., European Cities and Towns: 400-2000, Oxford-New York 2009.

Conceptualizations and Mental Processing in Language, ed. R.A. Geiger, B. Rudzka-Ostyn, New York 1993.

Duży W., City through Empires. Toruń (Poland) in an Ontology of Historical Geographic Information Systems from the 10th to 20th Centuries, w: Proceedings of the Digital Humanities Congress 2018, ed. L. Pitcher, M. Pidd, Sheffield 2018.
Eurostat, Applying the Degree of Urbanisation - A Methodological Manual to Define Cities, Towns and Rural Areas for International Comparisons, Luxemburg 2021.

Eurostat, Statistical Regions in the European Union and Partner Countries, Luxemburg 2020.

Evans A.J., Waters T., Mapping Vernacular Geography. Web-based GIS Tools for Capturing „Fuzzy” or ,Vague” Entities, „International Journal of Technology, Policy and Management”, 7 (2), 2008, s. 134-150. Farrokhi M., The Role of Legal Translation in the Interpretation of International Law Documents, „Russian Law Journal", 7 (1), 2019, s. 55-86.

Feldman Barett L., How Emotions are Made. The Secret Life of the Brain, New York 2017.

Gantner F. i in., The Basic Formal Ontology as a Reference Framework for Modeling the Evolution of Administrative Units, „Transactions in GIS”, 17 (2), 2013, s. 206-226.

Garbacz P., Ławrynowicz A., Szady B., Identity Criteria for Localities, w: Formal Ontology in Information Systems, ed. S. Borgo, P. Hitzler, O. Kutz, Amsterdam 2018, s. 47-54.

Giles J.A., Gildas, Cambridge, Ontario 2000.

Goźdź-Roszkowski S., The Role of Generic Competence and Professional Expertise in Legal Translation. The Case of English and Polish Probate Documents, "Studies in Logic, Grammar and Rhetoric”, 45 (1), 2016, s. 51-67.

Gregory I., Time-variant GIS Databases of Changing Historical Administrative Boundaries. A European Comaprison, „Transactions in GIS”, 6 (2), 2002. 
Guzowski P., Badania demograficzne nad rodzina wiejska w okresie staropolskim, w: Struktury demograficzne rodziny na ziemiach polskich do potowy XX wieku. Przeglad badań i problemów, red. P. Guzowski, C. Kukla, Białystok 2014, s. 11-31.

Guzowski P., The Present State and Prospects of Research on the Size of Poland's Population in the Late Middle Ages and at the Beginning of Early Modern Times, „Przeszłość Demograficzna Polski”, 37, 2015, s. 7-26.

Hallot P., Billen R., Enhancing Spatio-Temporal Identity. States of Existence and Presence, „ISPRS International Journal of Geo-Information”, 5 (5), 2016, s. 62 .

Handbook of Emotions, ed. L. Feldman Barett, M. Lewis, J. Haviland-Jones, New York 2016.

Harris T.M., From PGIS to Participatory Deep Mapping and Spatial Storytelling. An Evolving Trajectory in Community Knowledge Representation in GIS, „The Cartographic Journal”, 53 (4), 2016, s. 318-325.

Hayman E., Wedge M., James C., A Deep Chart (the Aqua-Face of Deep Mapping), „International Journal of Humanities and Arts Computing", 11 (1), 2017, s. 86-108.

Hejwowski K., Kognitywno-komunikacyjna teoria przektadu, Warszawa 2006.

Historical Atlas of Poland in the 2nd Half of the 16th Century. Voivodeships of Cracow, Sandomierz, Lublin, Sieradz, Eęczyca, Rawa, Ptock and Mazovia, ed. M. Słoń, Frankfurt am Main 2014 (Geschichte - Erinnerung - Politik. Studies in History, Memory and Politics).

Holt R., Rosser G., The English Medieval Town. A Reader in English Urban History 1200-1540, London 1990.

Hyvonen E. i in., Representing and Utilizing Changing Historical Places as an Ontology Timeseries, w: Geospatial Semantics and the Semantic Web. Foundations, Algorithms, and Applications, ed. N. Ashish, A.P. Sheth, New York 2011 (Semantic Web and Beyond).

Jakobson R., On Linguistic Aspects of Translation, w: On Translation, ed. R.A. Brower, New York 1966, s. 232-239.

Koller W., The Concept of Equivalence and the Object of Translation Studies 1, „Target. International Journal of Translation Studies", 7 (2), 1995, s. 191-222.

Kümin B., The Communal Age in Western Europe, c.1100-1800. Towns, Villages and Parishes in Pre-modern Society, Basingstoke 2013.

Kwieciński P., Disturbing Strangeness. Foreignisation and Domestication in Translation Procedures in the Context of Cultural Asymmetry, Torun 2001.

Lakoff G., Johnson M., Metaphors we live by, Chicago 2003.
Langacker R.W., Investigations in Cognitive Grammar, Berlin-New York 2009 (Cognitive Linguistics Research, 42).

Liddy C.D., Contesting the City. The Politics of Citizenship in English Towns, 1250-1530, Oxford-New York 2017 (Oxford studies in medieval European history).

Macháček J., The Rise of Medieval Towns and States in East Central Europe. Early Medieval Centres as Social and Economic Systems, Leiden-Boston 2010 (East Central and Eastern Europe in the Middle Ages, 450-1450, 10).

Malt B.C. i in., What Constrains Simultaneous Mastery of First and Second Language Word Use?, „International Journal of Bilingualism”, 20 (6), 2016, s. 684-699.

Marzo S., Heylen K., Sutter G. de, Corpus Studies in Contrastive Linguistics, Amsterdam 2012 (Benjamins Current Topics, 43).

Newmark P., Textbook of Translation, Herforshire 1998.

Nida E., Taber C., The Theory and Practice of Translation. With Special Reference to Bible Translating, Leiden 1982.

Pánek J., Emotional Maps. Participatory Crowdsourcing of Citizens' Perceptions of Their Urban Environment, „Cartographic Perspectives”, 91, 2019, s. 17-29.

Pavlenko A., Jarvis S., Bidirectional Transfer, „Applied Linguistics", 23 (2), 2002, s. 190-214.

Pavlenko A., Malt B.C., Kitchen Russian. Cross-Linguistic Differences and First-Language Object Naming by Russian-English Bilinguals, „Bilingualism. Language and Cognition", 14 (1), 2011, s. 19-45.

Poluszyński B., Strategie ttumaczeniowe stosowane podczas przektadu nazw wtasnych na przyktadzie wybranych polsko-angielskich artykutów z Wikipedii - analiza jakościowa i ilościowa, „Języki Obce w Szkole”, 4, 2012, s. 42-50.

Prusy Królewskie w drugiej potowie XVI wieku, oprac. M. Biskup przy współudziale L. Koca, Warszawa 1961 (Atlas Historyczny Polski. Seria B, Mapy przeglądowe 1).

Reiss K., Vermeer H.J., Towards a General Theory of Translational Action. Skopos Theory Explained, Hoboken 2014.

Rosch E., Cognitive Representations of Sematnic Categories, „Journal of Experimental Psychology”, 104 (3), 1975, s. 192-233.

Rudzka-Ostyn B., Word Power. Phrasal Verbs and Compounds. A Cognitive Approach, Berlin 2003 (Planet Communication).

Semantic and Lexical Universals, ed. C. Goddard, A. Wierzbicka, Amsterdam-Philadelphia 1994 (Studies in Language Companion Series, 25).

Sochaniewicz S., Wójtostwa i soltystwa pod względem prawnym i ekonomicznym w ziemi lwowskiej, Lwów 1921. 
Stano S., Eating the Other. A Semiotic Approach to the Translation of the Culinary Code, Newcastle upon Tyne 2015.

Swanson H., Medieval British Towns, London 1999.

The City of London from prehistoric times to c.1520, ed. M.D. Lobel, New York 1989 (British Historic Towns Atlas, 3).

Venuti L., The Scandals of Translation. Towards an Ethics of Difference, London-New York 1998.
Whorf B.L., Language, Thought, and Reality, ed. J. Carroll, Cambridge, Massachusetts 1957.

Wierzbicka A., Semantics. Primes and Universals, Oxford 1996.

Wierzbicka A., Understanding Cultures Through Their Key Words. English, Russian, Polish, German, and Japanese, New York 1997.

\section{On districts and manors. Influence of culture and language on translation into English of chosen terms from the domain of geohistory}

\section{Summary}

The article is the result of research with its main objective to propose a uniform method of analysis and choice of equivalent terms in the process of translation of concepts varying in terms of their spatial and historical evolution. It aims to present and analyse a range of problems that arise in translating texts on the history and geography of a particular region. The study has been based on the theory of translation (levels of equivalence), types and methods of translation, prototypicality, and ontological status of concepts. It is illustrated with an array of examples connected to the administrative and social structure divisions in Poland, which are as follows: województwo, powiat, wójt, miasto, folwark, zagrodnik, and komornik. The analysis is twofold and includes the methodological aspects of the translation process and the ontological status of the words and objects they relate to. The examples were analysed in following terms: 1) the divergence and overlap of the categories relating to the local administrative systems, 2) the diversity of the words depending on the location, and 3) their evolution in time. Based on that, a uniform way to present all features and reservations necessary to be included in the process of choosing the most appropriate equivalent was proposed. It was operationalised in the form of a table to account for all the arguments mentioned in the text. The examples were discussed and assessed numerically to indicate the key steps of the process.

Paulina Wacławik - absolwentka gospodarki przestrzennej (Wydział Geodezji i Kartografii, PW) oraz anglistyki (Wydział Neofilologii, UW), w swojej pracy łączy te dwie dyscypliny, zajmując się zagadnieniami na styku języka i kultury: transferem kulturowym, tłumaczeniem tekstów naukowych z dziedziny geografii i zastosowaniem narzędzi GIS w językoznawstwie; studentka studiów doktoranckich na Wydziale Neofilologii; tłumaczka (Paulina.h.waclawik@gmail.com)

Paulina Wacławik - graduate of spatial management (Faculty of Geodesy and Cartography, Warsaw University of Technology) and English studies (Faculty of Modern Languages, University of Warsaw); in her work, she combines these two disciplines, dealing with issues at the borderland of language and culture: cultural transfer, translation of scientific texts on geography and the use of GIS tools in linguistics; PhD student at the Faculty of Modern Languages; translator (Paulina.h.waclawik@gmail.com) 